\title{
The system of means of expressing the strategy of evasion in dialogical unity
}

\author{
Lyudmila Gushchina ${ }^{1 *}$ and Anna Nikolaeva ${ }^{1}$ \\ ${ }^{1}$ Southern Federal University, Bolshaya Sadovaya str., 105/42, Rostov-on-Don, 344006, Russia
}

\begin{abstract}
The research of the system of linguistic means, which express the strategy of evasion in dialogues within the framework of pragmalinguistics, contributes to a comprehensive study of this phenomenon, meeting the requirements of the nowadays scientific demands. The appeal to this topic is due to insufficient knowledge of the system of linguistic and pragmatic means that realize the strategy of evasion in dialogical speech. The aim of this paper describe the specifics of such language system analyzing some works of G. Ibsen, A. Miller, T. Williams and other well-known modern writers. The paper reveals the specifics of a dialogue as well as the phenomenon of speech influence, whose aim is to convince interlocutors consciously and / or unconsciously to accept someone else's point of view. The authors reveal the realization of the strategy of evasion in the dialogical unity studying some corresponding communicative tactics such as repetitions (including resentment, replay, reproach and overexpression), delay of response and mitigation of categoricity of response. All of them are represented by a great variety of multi-level linguistic means. The identified set of communicative tactics of the evasion strategy makes it possible to understand what communicative actions an addresser can perform to influence the addressee.
\end{abstract}

\section{Introduction}

Any communicative action is essentially a purposeful act. It has a distinctive feature of the desire to influence interlocutors, their opinions and beliefs. The research of communicative strategies and tactics of speech influence in general, as well as linguistic features of their implementation in particular, meets the current needs of modern society and is due to the presence of lacunae in the theory of social discourse. Communicative strategies, being the central object of this study, are analysed in this article from pragmalinguistics and speech influence viewpoints.

\footnotetext{
* Corresponding author: 1gushchina@sfedu.ru
} 
It goes without saying that the main task of any speech influence is to have impact on the addressee in order to induce him to do something beneficial to the speaker. Communication strategies implemented by appropriate communication tactics contribute to the success of the communication process. Speech tactics are a choice of speech actions that are formed in a dialogue and realized in a certain order.

If it is either impossible to reply in a direct way or necessary to hide the truth, the evasion strategy as a reaction to a previous statement is an effective communicative tactic of the recipient $[1,2]$. In general, the strategy of avoiding direct response is a type of speech response of one of the participants in the communicative situation of dialogical communication, which is due to the need to achieve a communicative goal that involves avoiding the answer. The strategy of speech behaviour is based on knowledge of principles of communication, intercultural communication and norms of speech etiquette.

The effectiveness of speech strategies is determined by the results or consequences of social interaction, regardless of whether the result is intentional, consciously planned.

\section{Methodology}

Communicative strategies of the linguistic personality are the subject of a significant number of Russian and foreign scholars of the XX-XXI centuries.

Discovering intersection zones with a number of different sciences and linguistic directions, issues of communicative strategies and tactics were actively discussed by psychologists, sociologists, psycholinguists, cognitologists and pragmalinguists (S.G. Agapova, I.V. Belyaeva, V.Z. Demyankov, E.L. Dotsenko, O.S. Issers, etc.).

Fundamental works in the field of communication strategies and tactics are devoted to the identification and presentation of the basics of speech impact (L.L. Fyodorova, T.G. Vinokur, I.A. Sternin); effective means of speech exposure (V.Z. Demyankov); psycholinguistic mechanisms of speech influence (A.V. Kinzel, V.N. Pankratov); speech manipulation phenomenon (S.G. Agapova, I.V. Belyaeva, K. Bredemeyer, S. Sorlin, etc.) [3]; communicative features of personality, validity and correctness of choice of linguistic means by an individual in specific conditions of communication (E. Bern, Y.S. Milkevich, I.A. Sternin) [4, 5]; identification and comparison of pragmalinguistic potential of individual language means (E.N. Malyuga, S.N. Orlova) [6-8].

Social discourse became the subject of a focused study of modern scholars such as M.M. Bakhtin, T.A. van Dijck, V.I. Karasik and others. The key aspects analysed by the researchers are the language circle, which includes the idea of personality, concept and discourse, etc. [9-11].

Despite the significant development by European scientists of theoretical and practical aspects of communication strategies and tactics, certain issues require further coverage. It is relevant to study the communicative strategy of evasion and expand ideas about features of its system of means of expression in dialogical unity. The appeal to this topic is due to the lack of knowledge of the system of linguistic means that implement a communicative strategy of evasion in dialogical speech, as well as the need to consider this issue from the perspective of several linguistic paradigms, namely, pragma, socio- and psycholinguistics, which provide a multidimensional and comprehensive study of this phenomenon.

The material of the analysis of this scientific paper is the dialogical unity selected by the method of continuous sampling from the works of G. Ibsen, A. Miller, T. Williams and others. The total sample size is 500 examples. 


\section{Results}

In the system of means of expressing the strategy of evasion, three types of tactics can be distinguished: 1) tactics of repetitions and interchanges; 2) response delay tactics; 3) tactics to mitigate categoricity of responses (Fig. 1). We consider the implementation of these tactics on the example of dialogical unity of plays.

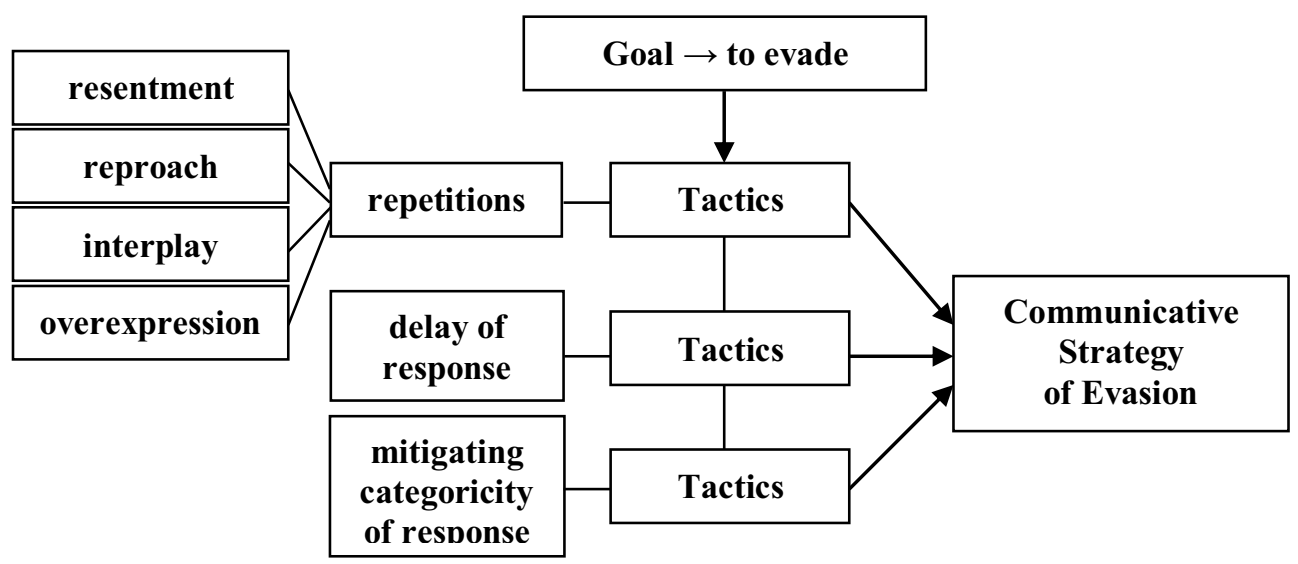

Fig. 1. Model of Communicative Strategy of Evasion

In an implicit speech act, the repetitions tactics is one of the most effective ones that help implement the evasion strategy. Using this tactics in a situation of speech communication, the speaker is able to evade a direct response, while transmitting some additional information.

In the language, the tactics of repetitions and reproaches as a means of evading a direct response within the evasion strategy are implemented through lexical repetitions, i.e. the repetition of one word or phrase in the composition of paired remarks [12, 13]. A remark stimulus is an indirect speech act that implements not only a global evasion function, but also a local illocutive function expressing a particular feeling.

So, for example, in A. Miller's play «The Death of a Salesman» in one of the scenes, the hero Biff wonders why he and Happy, his older brother, do not go together to the West: «Biff: Listen, why don't you come out West with me? Happy: You and I, heh?» (A. Miller). Happy's response vividly illustrates his disregard for the addressee of the question, Biff. The remark reaction serves as a means of implementing evasion. In addition, it conveys the emotional state of the hero of the play (Happy) who is surprised by the proposal of his younger brother Biff. He is not serious and ironic about this proposal. In his remark reaction, the evasion of a direct response is implicitly expressed by a speech act of surprise.

Repetition and overexpression tactics are characterized by increased expressiveness, i.e. an emotional perception of reality, which the addressee experiences and seeks to convey to his recipient, using, in particular, intensifier words. Thus, in dialogic unity, in which the tactics of repetitions and reproaches are represented, the use of simple intensifiers is observed, such as «such», «so», «all», «ever», «really», «even», «quite» and «absolutely». Remarks-reactions, which implement the tactics of repetition and interplay, have complex amplifying functions, which are quite difficult to distinguish from the emotive component. Amplification is basically a manifestation of confusion.

In the example borrowed from G. Ibsen's play «Doll House», the remark-reaction of the Anna-Maria is clearly expressive because of the use of the intensifier «such». The character resorts to the strategy of evasion realized by the tactics of repetition and reproach, clearly 
demonstrating the girl's unwillingness to give an immediate direct answer: «Nora: How could you do it? Anne-Marie: When I could get such a good place?» (G. Ibsen).

As noted above, repetition and interplay tactics are endowed with an emotional component if the words in the response line express emotions or feelings. The concepts of «emotion» and «feeling» should be distinguished: 'emotion' is a relatively short experience, while 'feeling' is a much more stable attitude to a phenomenon.

Our research has revealed a number of vocabulary and grammatical means of the language that represent the interrogative tactics:

$1)$ intensifiers and amplifying adverbs («such», «so», etc.);

2) colloquial oxymorons, in which two contrasting words contain antonymic meanings («terribly funny») are combined;

3) colloquial forms emphasizing freedom of communication («gonna see», etc.): «Biff: Well, all I said was I'm gonna see him, that's all! Willy: Then what're you talkin' about?» (A. Miller). Here, the colloquial form of the verb «go» - «gonna» is an identifier of the informal friendships of Biff and Willie. Willie's response repeats Biff's familial manner, which also testifies to the informal nature of the communication of the characters;

4) personal pronouns of the $1^{\text {st }}$ and $2^{\text {nd }}$ person which indicate the personal expression of the emotions of the communicant: «Rank: Why do you laugh at that? Do you have any real idea of what society is? Nora: What do I care about dreary old society?» (G. Ibsen). In this example, Nora forms her response line from the $1^{\text {st }}$ person, thereby moving away from other people and emphasizing her own feelings and ideas about the society surrounding her. A response is a remark that expresses some neglect;

5) simple and long-lasting verb forms, for example: «Linda (suddenly pleading): Will you please leave him alone? Biff: What is he doing out there?» (A. Miller). Therefore, in this example, Biff shows distrust in his mother's words. The form of the verb is both a means of expressing mistrust and a means of implementing the evasion of Linda's question;

6) modal verbs: «Amanda: Irish on both sides! Gracious! And doesn't drink? Tom: Shall I call him up and ask him right this minute?» (W. Tennessee). The fact is that Amanda looks at Tom's friend as a candidate for the role of a husband for her unmarried daughter and tries to find out some information about his identity. However, Tom shies away from the answer, implementing the tactics of questions in his response remark.

As a rule, it is stated that negation has a brighter emotionally expressive colouring than affirmation. So, the use of negation as a method of evasion should be distinguished as part of the tactics of repetition and overexpression. The presence of negation in the response lines makes them quite informative, since any negation implies contrast and creates an expressive potential. In addition, with the help of negation, it is possible to make phrases as multiple as possible, and at the same time expressively coloured. Negative constructions used as a means of implementing overrun tactics convey indecision or oscillation. For example: «Linda: Why are you so hateful to each other? Why is that? Biff: I'm not hateful. Mom.» (A. Miller). This example demonstrates the implementation of the lexical repetition of hatred in a response remark. The negative design of «I' $m$ not hateful» is implemented instead of the assumed necessary affirmative design of «I' $m$ friendly» and is the evidence of the manifestation of fluctuation or uncertainty by the character.

Thus, the communicative tactics of repetitions and interplays is an effective means of the evasion strategy, a type of speech response in a situation of dialogic communication.

In a situation of speech communication, the tactics of delaying the answer helps the speaker implicitly indicate a significant part of additional information or transfer an expressive function [14].

The main means of implementing response delay tactics are interjections. Interjections constitute a completely special layer of vocabulary. Let us discuss the implementation of the interjection «oh» as one of the means of communicative tactics of response delay: «Biff: 
Shouldn't we do anything? Linda: Oh, dear, you should do a lot of things, but there's nothing to do, so go to sleep» (A. Miller). Accompanied by the interjection «oh», Linda's answer to Biff's question sounds evasive, which indicates that the heroine does not want to continue the current conversation. A response remark is an indirect speech act, in which an illocutive function is implemented. Its purpose is to encourage the recipient to be inactive.

The analysis of the use of interjections in dialogical unity, representing the tactics of delaying the response, shows that a certain number of interjections can be distinguished, using which it seems possible to express specific feelings or emotional attitude to the conversation. For example, the interjections «humph», «hm», «er» and «uh» convey indecision or wobble: «Tom: You truly won't tell him that I owe you money? George: $\mathrm{Hm}-$ what if I told him that?» (E. Inchbald). George's confusion is transmitted in his response line with the interjection «hm». Using the tactics of delaying the response, the hero «wins»" some time to make up a decision about his further speech behaviour. In the given remark, which is an indirect speech act, the illocutive function of expressing the speaker's intentionality is implemented.

Also, the interjection «well» along with «humph», «hm», «er» and «uh» can act as a means of implementing response delay tactics. In the example below, it acts both as the answer itself and as a means of evasion, implementing the tactics of delaying the answer: «Jim: What do you think? Tom: Well...» (W. Tennessee).

The role of punctuation should be also noted as it marks important elements in the emotionally expressive plan, which are involved in the implementation of response delay tactics. When we use punctuation marks, the subtext of the emotional reaction is shifted in a way. In this case, the speaker breaks off his speech without completing the idea, preferring that the interlocutor will independently guess what they are talking about: "Willy: I'm out! So tell me, he gave you a warm welcome? Biff: Well, it was kind of $=\gg$ (A. Miller). Here, the character's father wonders if his employer properly treated his son. However, the fact is that according to the plot of the play, Biff did not meet with the employer. Therefore, in order not to upset his father and not to cause an undesirable negative reaction on his part, in his remark, saturated with pauses, he evades the answer using delay tactics, in which the means of implementing evasion are both the interjection «well» and the punctuation mark «dash».

So, the response delay tactics are represented by verbal components of speech, such as: the interjections «humph», «hm», «er» and «uh», transmitting indecision or oscillation; the interjection «well», which also gives an emotional-expressive connotation to the speech; and punctuation marks that indicate emotional and prolonged pauses.

The tactics to mitigate the categoricity of response is one of the most diplomatic tactics, since it allows communicants to evade a direct response and makes it possible for them to reduce the general tense tone of the conversation, divert attention from the problem that causes irritation or indignation and win the interlocutor over [15].

Our analysis has revealed that the means of implementing tactics to mitigate the categoricity of the response can be lexico-grammatical (proper names, modal words) and syntactic (appeals, introductory phrases) means.

Modal words are lexico-grammatical means of implementing tactics of response mitigation. They fulfill an additional illocutive function of the communicant's own attitude to the subject of the speech. Being used to implement response mitigation tactics at the beginning of the sentence, they apply to the entire sentence, acting as an introductory member of the sentence, for example: «Nora: If it has to happen, then it's best it happens in silence - don't you think so? Jane: Maybe it's best this way» (G. Ibsen).

The use of proper names in dialogic communication can also favourably affect the course of the conversation, allow the participants of communication to establish personal contact and soften the general tense tone of the conversation. By implementing the strategy 
of avoiding a direct answer, the speaker can deliberately turn to the name of the interlocutor as a mitigation of the categoricity of the answer. The use of the tactics to mitigate the categoricity of the response allows you to evade a response diplomatically without a supposed negative reaction.

The dialogue in the following example is based on the interaction of interlocutors with different social statuses: a university professor and his student. The professor does not intend to evaluate Judy's final work because the quality of the work leaves much to be desired. However, the heroine asks the professor for leniency. In response, the professor evades the answer, resorting to the mitigation tactics, implemented with Miss Miller's appeal. Thus, he tries to activate the «adult» personality qualities in Judy, such as responsibility and seriousness: «Judy: Couldn't you give me partial credit? For the idea? Henry: Miss Miller, how can I?» (A. Gurney).

Along with the address by name, appeals indicating related ties between communicants of dialogic communication can act as means of implementing the tactics for mitigating the response. At first glance, the presence of family relations should reduce the likelihood of using a strategy of avoiding a direct response, since family relations are canonically based on sincerity and trust. However, the results of our research indicate the functioning of the tactics to mitigate the categoricity of the response in conditions of domestic dialogue, for example: «Amanda: Why? Why? How old are you, Laura? Laura: Mother, you know my age» ( $W$. Tennessee). In such situations, Laura shies away from answering the questions of her mother Amanda. The character realizes that she does not calm her mother, but, on the contrary, increases her level of anxiety. However, the appeal of «mother» in the response lines softens the tense tone of the conversation.

The phrases like «don't get insulted», «sorry», «don't worry», etc. also function as tools that implement the tactics to mitigate categorical responses. These structures allow the speaker to both get away from the answer and calm the interlocutor, softening the general tone of the dialogue. So, in the example below, Charlie's remark functions as soothing and reassuring Willie.

The introductory sentences such as «you know», «I think», «I guess», «I believe» and «I hope» act an introductory member, being related to the sentence in which they are used both in content and grammatically. In the tactics of mitigating the categoricity of the response by value, the introductory member of the proposal is correlated with the content of the entire proposal. The introductory member of a sentence is related to the entire sentence by a relation, which is formally expressed in its inclusion in the sentence without a fixed place, but in retaliatory remarks of the mitigation tactics. Introductory phrases and sentences usually stand at the beginning of the remark, for example: «Jim: Hope you don't think I'm being too personal - do you? Laura: I believe I will take a piece of gum, if you don't mind» (W. Tennessee).

Thus, the tactics of mitigating the categoricity of the answer are represented by the vocabulary and grammatical means of the language: modal words; proper names; and syntax of the language: introductory phrases and sentences; appeals that indicate the kinship of speakers or their social status.

\section{Conclusion}

In this article, a pragmalinguistic analysis of the communicative strategy of evasion and the corresponding tactics used in dialogic speech, in particular in social and everyday dialogues in modern fiction, was carried out.

Being the main type of communication, dialogue has a certain set of characteristics, including two or more participants, connectivity and alternation of statements, ad hoc arrangements and involuntary, the use of the principle of saving efforts. 
Participants in the dialogue, like in any other form of speech, are exposed to the influence on the interlocutor, which is aimed at convincing him or her to consciously and / or unconsciously accept someone else's point of view. Speech exposure is carried out by certain communicative strategies and tactics.

The communicative strategy of evasion is represented by the tactics of: 1) repetitions, which allow you to implement a diplomatic scenario of speech interaction, contributing to veiling, concealing the true meaning of the response remark, or completely evading a direct response; 2) delay of response, represented by verbal and non-verbal components of speech, which convey indecision and / or oscillation, give answers with emotionally expressive connotation; 3) mitigating categoricity of response.

The identified set of communicative tactics of the evasion strategy makes it possible to understand what communicative actions a speaker can perform to carry out speech effects on the recipient.

\section{References}

1. J. Tsoumou, Journal of Pragmatics, 167, 80-97 (2020) doi:10.1016/j.pragma.2020.06.004

2. J. Chovanec, Jounal of Pragmatics, 158, 66-79 (2020) doi:10.1016/j.pragma.2020.01.003

3. S. Sorlin, Journal of Pragmatics, 121, 132-146 (2017) doi:10.1016/j.pragma.2017.10.002

4. A. Jamshidnejad, Journal of Pragmatics, 15, 3757-3769 (2011) doi:10.1016/j.pragma.2011.09.017

5. E. Severina, S. Agapova, Ye. Milkevich, E. Agapova, Intern. J. of Interdisciplinary Cultural Studies, 13, 15-28 (2018) doi:10.18848/2327-008X/CGP/v13i01/15-28

6. F. Mardian, Journal of Pragmatics, 174, 125-127 (2021) https://doi.org/10.1016/j.pragma.2021.01.006

7. N. Volskaya, L. Borbotko, M. Zheltukhina, M. Kupriyanova, A. Ilina, XLinguae, 4, 84-95 (2017) doi:10.18355/XL.2017.10.04.08

8. I. Aleshchanova, N. Frolova, M. Zheltukhina, Advances in Social Science, Education and Humanities Research, 331, 5-11 (2019) https://doi.org/10.2991/ismge-19.2019.2

9. M. Zheltukhina, M. Busygina, M. Merkulova, I. Zyubina, L. Buzinova, XLinguae, 11, 639-654 (2018) doi:10.18355/XL.2018.11.02.51

10. S. Tinshe, CELTIC: A Journal of Culture, English Language Teaching, Literature \& Linguistics, 6, 73-87 (2019) https://doi.org/10.22219/celtic.v6i2.9947

11. V. Melikyan, A. Melikyan, A. Dzyubenko, Zeitschrift für Slawistik, 62, 23-47 (2017) doi:10.1515/slaw-2017-0002

12. K. Marian, T. Malabarba, A. Weatherall, Language \& Communication, 78, 77-87 (2021) doi:10.1016/j.langcom.2021.01.004

13. C. Raymond, Language \& Communication, 42, 50-68 (2015) https://doi.org/10.1075/slsi.31.03ray

14. D. de Souza, E. Betz, M. Clinkenbeard, et al, Language \& Communication, 76, 47-57 (2021) https://doi.org/10.1016/j.langcom.2020.09.005

15. J. Roche, B. Peters, R. Dale, Speech Communication, 66, 47-64 (2015) doi:10.1016/j.specom.2014.07.004 